\title{
Estudo comparado da morfologia externa de Zaretis itys itylus (Westwood) e Agrias claudina annetta (Gray). (Lepidoptera, Nymphalidae, Charaxinae) II. Tórax e apêndices 1
}

\author{
Carlos Guilherme C. Mielke ${ }^{2}$, Olaf H. H. Mielke ${ }^{3} \&$ Mirna M. Casagrande ${ }^{3}$ \\ ${ }^{1}$ Contribuição número 1292 do Departamento de Zoologia, Universidade Federal do Paraná. \\ ${ }^{2}$ Caixa postal 1206, 84145-000 Carambeí, Paraná, Brasil.E-mail: cmielke1@uol.com.br \\ ${ }^{3}$ Laboratório de Estudos de Lepidoptera Neotropical, Departamento de Zoologia, Universidade Federal do Paraná. Caixa \\ Postal 19020, 81531-980 Curitiba, Paraná, Brasil. Pesquisador do CNPq. E-mail: omhesp@ufpr.br; mibras@ufpr.br
}

\begin{abstract}
Comparative study of the external morphology of Zaretis itys itylus (Westwood) and Agrias claudina annetta (Gray). II. Thorax and appendages (Lepidoptera, Nymphalidae, Charaxinae). Two species of Charaxinae, Zaretis itys itylus (Westwood, 1850) and Agrias claudina annetta (Gray, 1832) were subject of a detailed and comparative study of external morphology of the thorax and appendages. The results obtained were compared with other studies published and related to the external morphology of other Nymphalidae (Brassolinae, Morphinae, Danainae and Ithomiinae), Lycaenidae, Saturniidae and Sphingidae.

KEY WORDS. Neotropical, butterflies, morphology, comparative study
\end{abstract}

RESUMO. Realizou-se um estudo detalhado e comparado da morfologia externa do tórax e apêndices de duas espécies de Charaxinae, Zaretis itys itylus (Westwood, 1850) e Agrias claudina annetta (Gray, 1832). Os resultados obtidos foram comparados com outros já publicados e relacionados com morfologia externa de outros Nymphalidae (Brassolinae, Morphinae, Danainae e Ithomiinae), Lycaenidae, Saturniidae e Sphingidae.

PALAVRAS CHAVE. Borboletas, estudo comparado, morfologia, neotropical.

Esta é a segunda contribuição ao estudo morfológico externo e comparado de Zaretis itys itylus (Westwood, 1850) e Agrias claudina annetta (Gray, 1832). Aspectos taxonômicos, material e metodologia utilizada, como mencionado na primeira contribuição (MieLKe et al. 2004).

\section{RESULTADOS}

\section{Considerações sobre a terminologia}

A terminologia empregada no presente estudo segue, principalmente, àquela adotada por EHRLICH (1958a) no trabalho sobre a morfologia de Danaus plexippus (Linnaeus, 1758). Considerando-se as divergências na literatura quanto à nomenclatura de certas estruturas e novos conceitos apresentados em artigos mais recentes, comenta-se a seguir alguns destes aspectos.

\section{Protórax}

SNodgrass (1935) e Madden (1944), consideram que o epimero I desaparece, embora a sutura pleural I esteja presente internamente. SORENSEN (1980) concorda com a presença da sutura pleural I, e identifica o epimero I composto, na maior parte por membrana. Michener (1952), Ehrlich (1958a), CASA- grande (1979), Bilotta (1995) e Bizarro et al. (2003) referem-se ao episterno I como pleura I.

Para Sorensen (1980), o basisterno I encontra-se invaginado, formando o sulco mediano longitudinal. Para EHRLICH (1958a), Casagrande (1979), Bilotta (1995) e Bizarro et al. (2003), tal sulco é denominado de discrime I.

\section{Mesotórax}

Os espiráculos presentes no tórax das lagartas de Lepidoptera (Hinton 1946, STEHR 1987), aparecem no primeiro e terceiro segmentos, sugerindo a origem pró e metatorácica destes nos adultos. Verifica-se, no entanto, uma omissão na determinação destas estruturas na literatura. EhrLICH (1958a), Casagrande (1979), Bilotta (1995) e Bizarro et al. (2003) referem-se aos mesmos como primeiro e segundo espiráculos.

Embora Ehrlich (1958a) mencione a presença de uma sutura que separa o pré-escuto II do escuto II, ele não a denomina. Esta é determinada por Matsuda (1970) como sutura préscuto-escutal.

Michener (1952), Ehrlich (1958a), Casagrande (1979), Bilotta (1995) e Bizarro et al. (2003) consideram a divisão do epimero II em duas partes, uma pré e outra pós-alar. MATSUDA 
(1970) refere-se à porção pós-alar do epimero como ponte pósalar, considerando haver uma associação dessa com a margem posterior do láterofragma, como uma derivação do pós-noto, conforme SHarplin (1963b). Tal associação é verificada nas espécies estudadas neste trabalho e por esta razão segue-se Matsuda (1970).

A subtégula e o apódema tergopleural recebem diversas denominações. MADDEN (1944) cita o conjunto como subtégula, composta de uma placa anterior e uma posterior; Michener (1952), EhrLich (1958a) e CASAGRANDE (1979) referem-se a estrutura como braço tegular; SHARPLIN (1963a) menciona a porção anterior como subtégula e a posterior como apódema tergopleural; considerando a evidência das duas estruturas, segue-se este autor.

Brock (1971) refere-se à sutura pré-coxal de EHRLICH (1958a), Casagrande (1979), Bilotta (1995) e Bizarro et al. (2003) como sutura esternopleural. Optou-se por sutura pré-coxal, mantendo a designação mais antiga. Da mesma forma utilizou-se o termo basisterno II, termo empregado por MADDEN (1944) para esternopleurito II de EнrLICH (1958a).

Segundo Michener (1952), Ehrlich (1958a), Casagrande (1979), Bilotta (1995) e Bizarro et al. (2003) o basisterno separa-se da eucoxa pela sutura marginopleural, já para Ввоск (1971) a sutura paracoxal em Papilionoidea surge fusionada à sutura marginopleural de SHEPARD (1930).

Embora EhrLich (1958a) mencione o pré-epimero separado do epimero, não nomina a sutura que os divide. Adota-se o termo empregado por Sorensen (1980), sutura pré-epimeral.

\section{Metatórax}

A porção látero-ventral segue como no mesotórax, logo, apenas as diferenças são relatadas.

\section{Escleritos axilares}

Formados de muitas peças, fazem a articulação das asas com o tórax. A placa umeral, mencionada por MADDEN (1944), é denominada por EhrLich (1958a) como processo basal da subcosta. Este mesmo autor considera o segundo axilar bilobado em vista dorsal, sendo um lóbulo proximal e um distal. Para MAdDen (1944) e EhrLich (1958a) o quarto axilar, articulado com o terceiro, encontra-se fundido ao processo notal posterior da asa II, porém distinguem-se por um estreitamento entre os dois. Para Scoble (1992) o quarto axilar pode ou não estar presente, mencionando sua presença funcional nos Incurvarioidea e nos Ditrysia primitivos. No metatórax poucas diferenças são evidenciadas, além do formato destes escleritos. EHrLıch (1958a) registra o esclerito costal como uma projeção esclerotinizada junto à base de Sc+R; SHARPLIN (1963b) designa tal estrutura como processo basal do cúbito, não evidenciada em Charaxinae.

\section{Pernas}

Madden (1944), Michener (1952), Ehrlich (1958a), Casagrande (1979), Scoble (1992), Bilotta (1995) e Bizarro et al. (2003) referem-se ao mero como a porção posterior da coxa, uma vez que esta é dividida pela sutura coxal. O basicoxito para Michener (1952), Ehrlich (1958a) e Casagrande (1979) é um esclerito pequeno e presente no ápice da sutura coxal. Tanto Ehrlich (1958a) quanto Casagrande (1979), Scoble (1992), BilotTa (1995) e Bizarro et al. (2003) usam o termo eucoxa para a porção anterior à sutura coxal e mero para a posterior.

A definição das estruturas do pré-tarso, mencionadas como pouco esclerotinizadas e pouco demarcadas (EHrLich 1958a), parece ser confusa na literatura. Goel \& SCHAEFER (1970), chamam a região entre os pulvilos de basipulvilo, estando aparentemente conectada à placa ungüitratora. Segue-se a terminologia de EHRLICH (1958a).

\section{Zaretis itys itylus (Westwood, 1850)}

\section{Figs 1-14}

\section{Protórax}

Noto I composto de duas partes; uma delas, a placa dorsal, com formato de um cálice de base ligada ao pré-escuto II, deprimida nas extremidades anterior e posterior, possui duas projeções ântero-laterais que alcançam os patágios; a outra, anterior à dorsal, é formada pelas placas laterais fundidas na linha mediana dorsal e articuladas por expansões látero-posteriores com a placa dorsal, látero-ventral articuladas com o episterno I. Ântero-dorsalmente no pronoto, duas estruturas esclerotinizadas globulares, os patágios, se estendem até a região látero-mediana do protórax. Posteriormente, menores que os patágios e de pouca esclerotinização, os parapatágios estão inseridos na membrana; estendem-se látero-ventralmente até pouco abaixo dos patágios, onde posteriormente encontra-se o $1^{\circ}$ espiráculo torácico. Látero-ventralmente às placas laterais, o episterno I circunda o corpo, fusiona ventralmente com o lado oposto; a margem posterior é caracterizada pela sutura pleural I. Anterior ao episterno I está o pré-esterno I, losangular. Póstero-ventralmente a este esclerito tem-se o trocantin, esclerito estreito e longitudinal que forma ventralmente junto com o episterno I, a articulação pleural da coxa I. A margem póstero-ventral do episterno I, na porção mediana, articula a um esclerito transverso com a porção anterior triangular em vista ventral; em vista lateral em forma de $S$, onde a base dá suporte para duas aberturas laterais, uma de cada lado, originando dois tubos internos no corpo do inseto. Articulado posteriormente, um esclerito estreito nas extremidades e alargado medianamente, a furca I, está invaginada e articula com o espinasterno I, dando origem à fóvea do espinasterno I. Este, entre catepisterno direito e esquerdo apresenta a metade anterior triangular e mais esclerotinizada que a posterior.

\section{Mesotórax}

Maior segmento torácico. Noto II alargado medianamente e, dividido em três escleritos: pré-escuto, escuto e escutelo. Anteriormente, o menor deles, o pré-escuto é curvado em direção ventro-anterior para articular com o noto I; uma projeção ventral de margem ântero-ventral bilobada caracteriza internamente o primeiro fragma. Pré-escuto com duas projeções, 


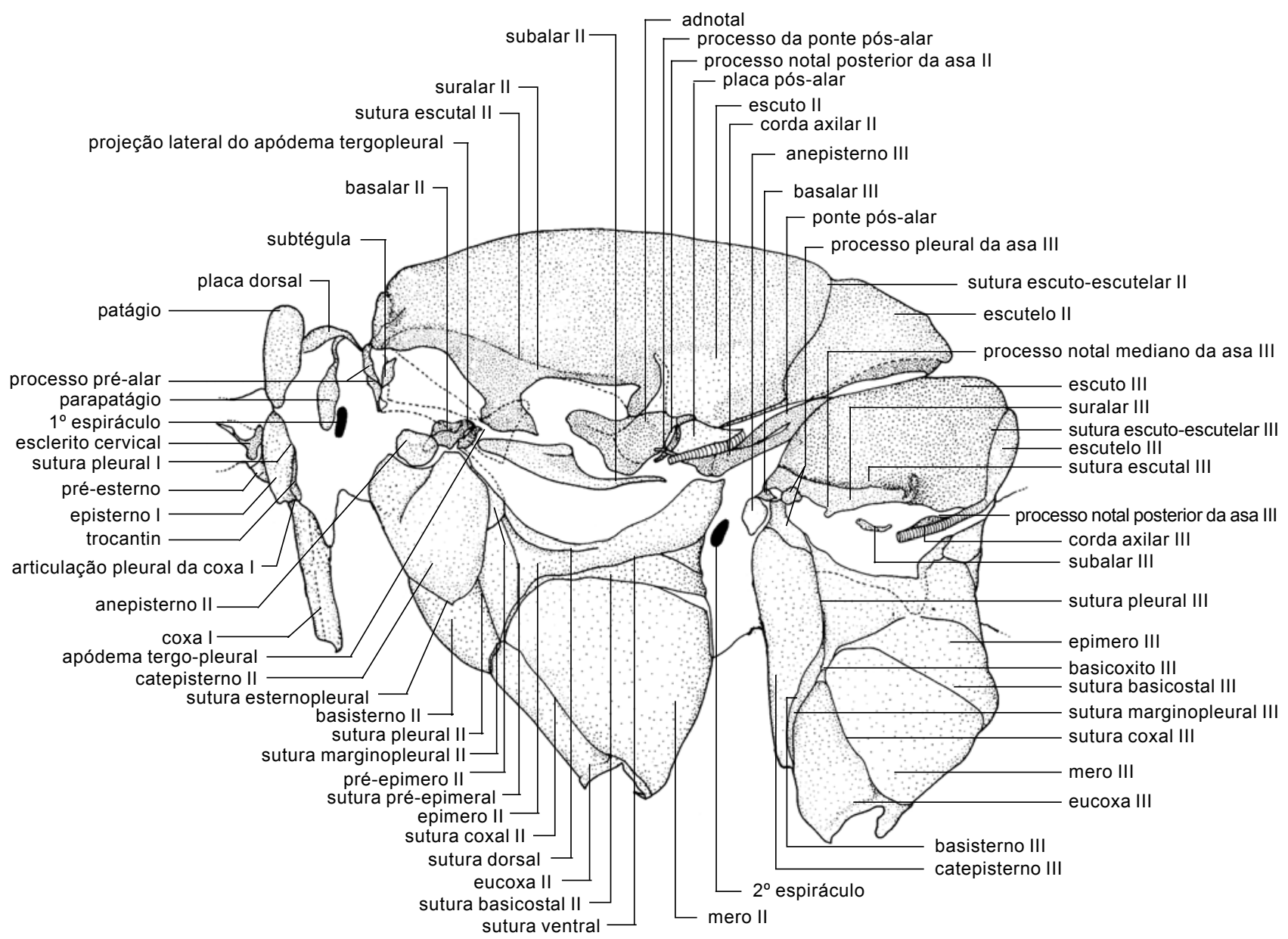

Figura 1. Zaretis itys itylus, tórax - vista lateral.

uma a cada lado, o processo pré-alar, estendido látero-ventralmente, se bifurca na porção lateral para articular com a margem ventral da subtégula. Tégula articulada a subtégula ventralmente, com a porção anterior mais larga, afilando posteriormente. Apódema tergopleural, estendido posteriormente, articula ântero-dorsalmente com a subtégula e emite projeção lateral na porção posterior que funde com o processo pleural da asa II, além de estar conectado ao catepisterno II internamente. Metade dorsal do pré-escuto com uma linha mediana fraca prolongada posteriormente para formar a linha mesoescutal que no escuto II é distinta e o divide longitudinalmente. Este último, o maior esclerito, separa-se do pré-escuto pela sutura préscuto-escutal. De cada ângulo ântero-lateral do escuto II, projetado sobre o pré-escuto, origina-se uma placa lateral, a suralar II, estendida posteriormente até a região mediana ventral e separada do mesmo pela sutura escutal II, terminando junto a uma projeção do escuto II em forma de vírgula. Escutelo II, separado do escuto II pela sutura escuto-escutelar II, possui aspecto triangular em vista dorsal, sendo os catetos arredondados e a hipotenusa projetada para dentro do escuto II, na porção mediana. Este esclerito projeta-se ântero-lateralmente por processos delgados até a porção posterior do adnotal, uma expansão póstero-ventral do escuto II. O adnotal apresenta-se bilobado, caracterizado por um lobo mediano e outro ventral, e projetado anteriormente para junto com a suralar II articular com o primeiro esclerito axilar. Lateralmente à porção pósteroventral do escuto II situa-se a placa pós-alar de aspecto losangular e ladeada por membrana látero-posteriormente. Lateralmente, tal membrana dá origem à corda axilar II. Na margem interna, a placa pós-alar fusiona com o escuto II formando um $\mathrm{V}$ invertido, logo baixo desse, a projeção ântero-lateral do escutelo conecta-se ao adnotal. Fusionado anteriormente com a placa pós-alar e articulando com o escuto II, um esclerito transverso, o processo notal posterior da asa II, articula distalmente com o terceiro axilar. Porção membranosa da placa pósalar sustentada pela ponte pós-alar surge da inserção no pós-

Revista Brasileira de Zoologia 21 (3): 421-433, setembro 2004 


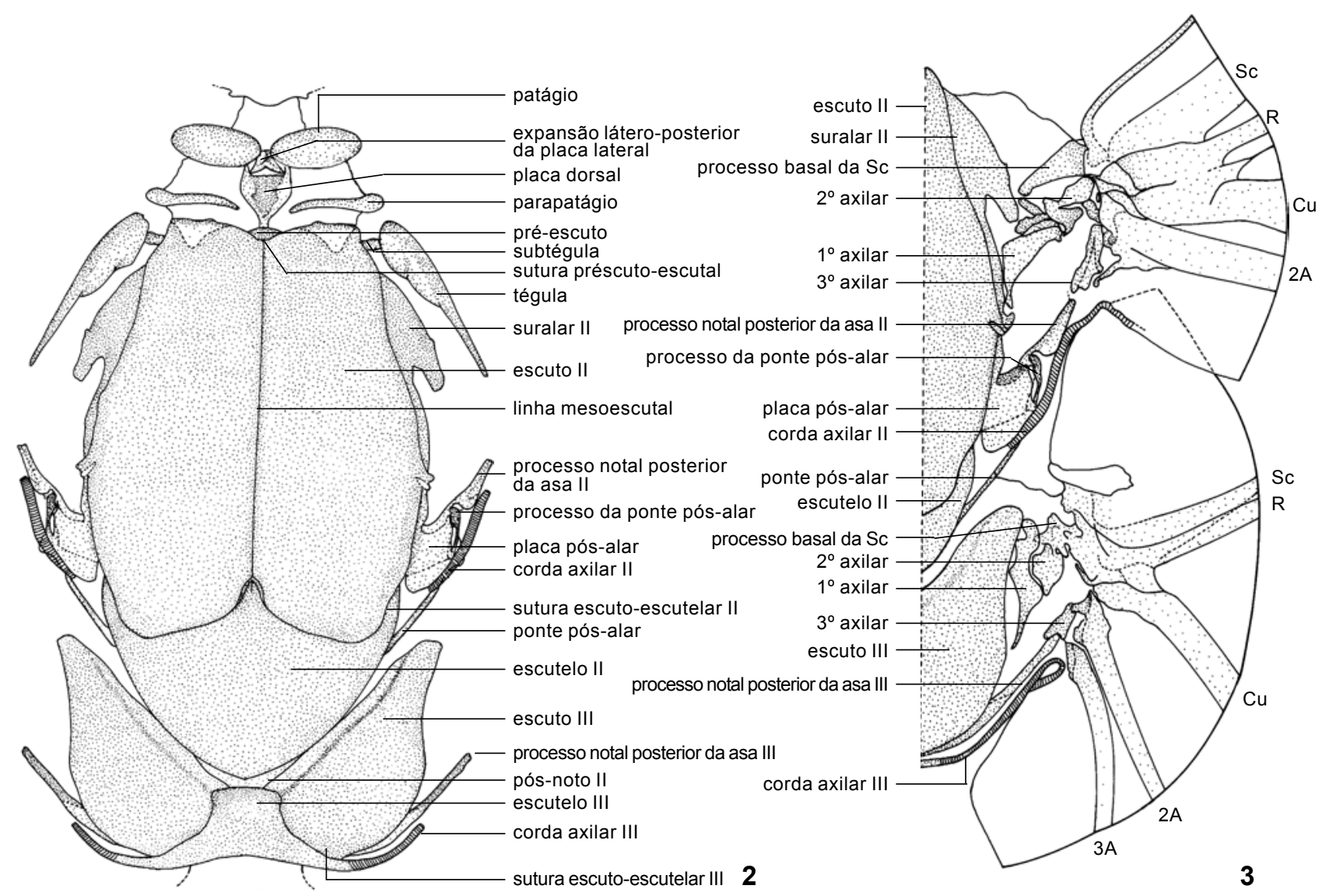

Figuras 2-3. Zaretis itys itylus, tórax:(2) vista dorsal; (3) escleritos axilares.

noto II, projetando-se ântero-ventralmente para articular com o epimero II. Nota-se longitudinalmente a este, na região mediana, uma área diferenciada: o processo da porção pós-alar do epimero aqui tratada como processo da ponte pós-alar. Este processo é o resultado da fusão de um lobo da placa pós-alar com o propriamente dito processo da ponte pós-alar. Tal estrutura projeta-se dorsalmente, ultrapassa a membrana, e articula com o processo notal posterior da asa II. Póstero-ventralmente ao escutelo II e separado por membrana, o pós-noto II forma ventralmente o segundo fragma. Este esclerito projetado anterior e internamente, funde ao adnotal, assim como as projeções látero-anteriores do escutelo II. O segundo fragma, bilobado ventralmente e com as margens externas retas; caracterizado por partes mais esclerotinizadas, sendo duas bandas nas porções laterais e um $U$ invertido que acompanha a margem na região mediana, entre os lobos.

Pleura II dividida em duas partes: uma anterior, o episterno II e uma posterior, o epimero II. Episterno II, separado do epimero II pela sutura pleural II desde a porção superior até a base da coxa, encontra-se dividido em anepisterno II e catepis- terno II, separados entre si por membrana; ântero-dorsalmente o primeiro, circular e menos esclerotinizado que o segundo. Derivada da sutura pleural II, a sutura esternopleural II corre em direção ântero-ventral encontrando com o espinasterno II. Tal sutura separa o catepistermo II do basisterno II, fundido ao lado oposto através do discrime II. O basisterno II segue posteriormente entre as coxas e expande-se lateralmente para a formação da articulação ventral da coxa II. Discrime II, marcado por uma lamela forte internamente, é interrompido pela fóvea apofisial II. A parte posterior da mesopleura é composta pelo epimero II. Na porção ântero-dorsal, o pré-epimero II, delimitado pela sutura pré-epimeral, e acima dessa, curva-se de forma transversal à sua origem, constituindo o processo pleural da asa II que funde-se à projeção lateral do apódema tergopleural. O epimero II é dividido longitudinalmente pela sutura ventral do epimero II até a porção ântero-ventral bifurcandose posteriormente, formando um esclerito triangular, projetado internamente; partindo da região ântero-dorsal tem-se a sutura dorsal do epimero II incompleta. O esclerito pós-coxal está presente na porção posterior do epimero II não sendo visí- 


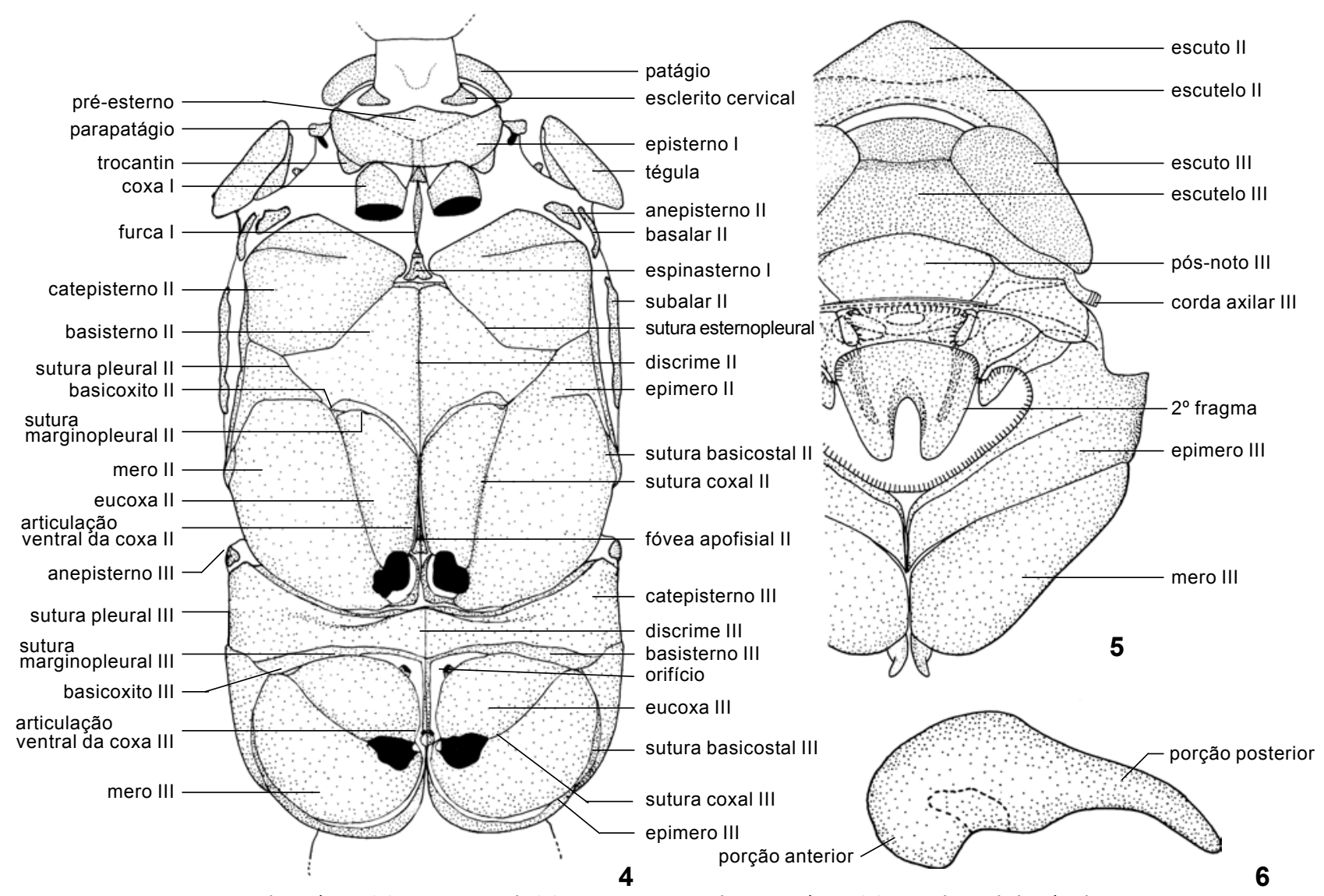

Figuras 4-6. Zaretis itys itylus, tórax: (4) vista ventral; (5) vista posterior do metatórax; (5) vista lateral da tégula.

vel lateralmente. A coxa ocupa grande parte do mesotórax e está delimitada anteriormente pela sutura marginopleural II. Entre o noto e a pleura, o basalar II irregular e ladeado por membrana, logo acima do anepisterno II onde articula com a projeção lateral do apódema tergopleural e com o processo pleural da asa II. Dorsal ao epimero II, com aproximadamente o seu comprimento e ladeado por membrana, o subalar II.

\section{Metatórax}

Posteriormente ao epimero II, na região membranosa, encontra-se o segundo espiráculo. O metatórax é o segundo maior esclerito do tórax, constituido pelo escuto III quase que totalmente dividido pelo escutelo III, se não por uma estreita ligação na porção mediana anterior; estes separados entre si pela sutura escuto-escutelar III. Escuto III, retangular em vista lateral, situa-se parcialmente abaixo do escutelo II. Na porção ântero-ventral está a suralar III, separada do escuto III pela sutura escutal III e delimitada de forma incompleta posteriormente. A projeção do escuto III é menos evidente neste segmento e assim como no anterior, uma região de textura diferenciada na parte posterior. Na margem ventral do suralar III estão os processos notais anterior, mediano e posterior da asa
III. Processo notal posterior da asa III destaca-se por ser longo e por articular com o terceiro esclerito axilar. Escutelo III em vista dorsal é deprimido anterior e posteriormente e projetado látero-anteriormente, passando a membranoso para formar a corda axilar III. Pós-noto III, póstero-ventralmente ao escutelo III, apresenta uma placa retangular duas vezes mais larga que comprida.

Pleura III é dividida pela sutura pleural III, demarcando o episterno III e o epimero III. Porção anterior, episterno III, composta dorsalmente pelo anepisterno III, semimembranoso e separado dos demais por membrana, látero-ventralmente do catepisterno III, este mais o basisterno III, se estreitam ventralmente até a porção mediana da eucoxa III, unido ao lado oposto pelo discrime III, que continua posteriormente entre as coxas, alargando entre as mesmas para formar a articulação ventral da coxa III. No epimero III a sutura dorsal do epimero III é pouco demarcada enquanto a ventral é incompleta. Ânterodorsalmente ao epimero III, o processo pleural da asa III é dividido em duas porções e delimitado pelo prolongamento dorsal da sutura pleural III; póstero-dorsalmente algumas suturas prolongadas para a região posterior do tórax delimitam um con-

Revista Brasileira de Zoologia 21 (3): 421-433, setembro 2004 


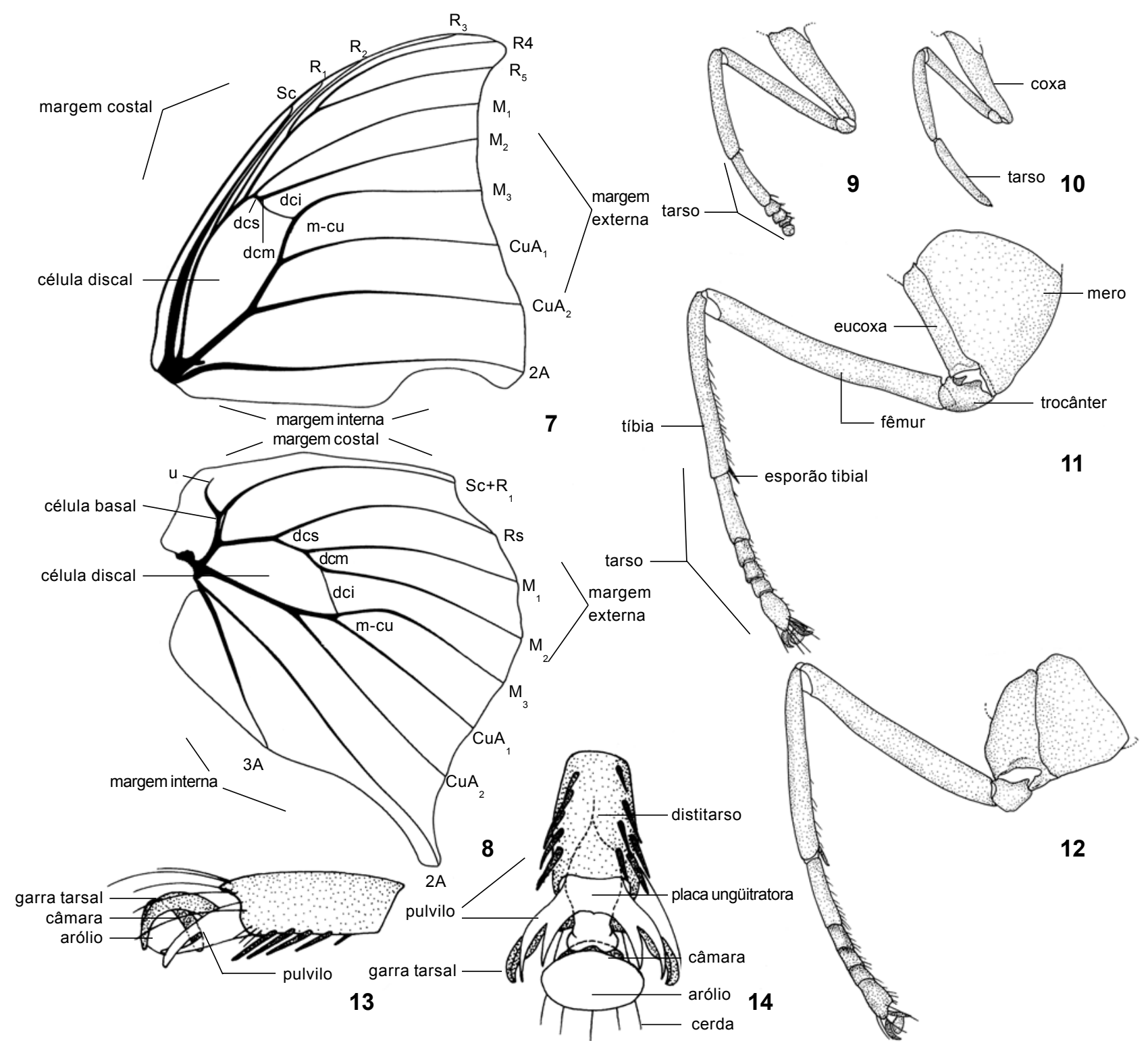

Figuras 7-14. Zaretis itys itylus, (7) asa anterior; (8) asa posterior; (9 - 12) pernas vista lateral: (9) protorácica da fêmea, (10) protorácica do macho, (11) mesotorácica, (12) metatorácica; (13-14) distitarso (13) vista lateral, (14) vista ventral.

junto de escleritos responsáveis pela articulação do tórax com o abdome. Separando o basisterno III da coxa, na porção láteroventral, a sutura marginopleural III. Uma estrutura, presente em ambos os sexos, de função não identificada e sem correlata na bibliografia, na forma de orifício ocupa a porção anterior da eucoxa III. Entre as coxas a fóvea apofisial III. Basalar III, irregular e menor que o basalar II, e dorsal ao anepisterno III, e o subalar III, menor que o subalar II, ladeado por membrana, encontra-se sobre o epimero III.

\section{Asas e escleritos axilares}

Asa anterior de formato triangular em ambos os sexos, no entanto, na fêmea mais expandida externamente; é delimitada pela margem costal convexa em toda a sua extensão, culminando com o ápice pronunciado; margem externa côncava, nos três quartos superiores e, convexa no quarto inferior. Margem interna com notável reentrância junto ao ângulo anal, no terço distal. Margem externa da asa da fêmea côncava no terço superior e convexa no dois terços inferiores. Venação compos- 


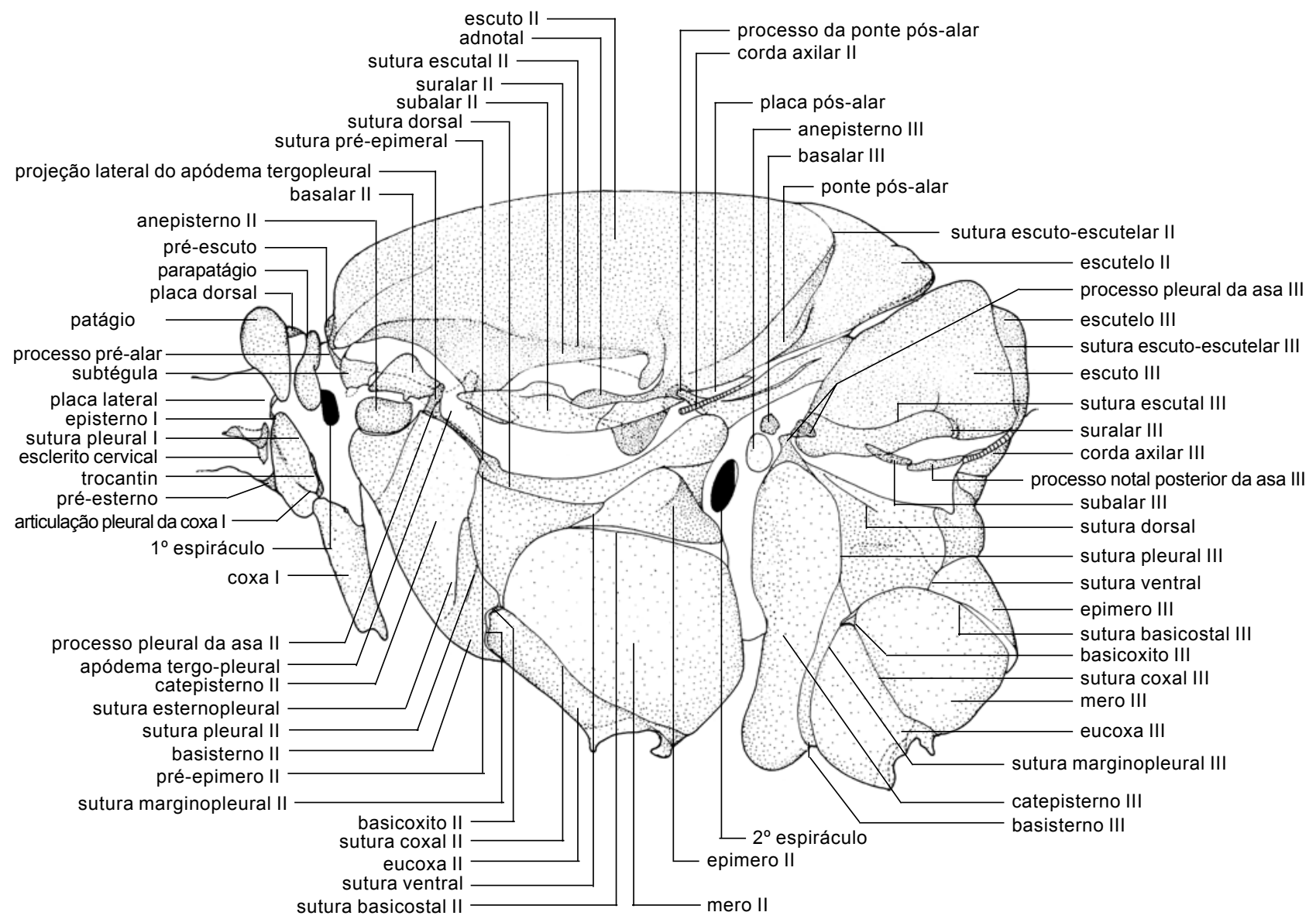

Figura 15. Agrias claudina annetta, vista lateral.

ta pela Sc, R, M, CuA e A. Subcosta (Sc), inicialmente espessa, termina no terço mediano da margem costal. Radial (R) bifurca-se em $\mathrm{R}_{1}$ e $\mathrm{R}_{\mathrm{s}} ; \mathrm{R}_{1}$ inicia-se no final do terceiro quarto da célula discal e termina no final do segundo terço da margem costal; $R_{s}$ dividida em $R_{2}, R_{3}, R_{4}, R_{5}$. $R_{2}$ inicia-se na célula discal entre $\mathrm{R}_{1}$ e $\mathrm{R}_{3}+\mathrm{R}_{4}+\mathrm{R}_{5}$ e termina na margem costal no final do terceiro quarto da célula. $R_{3}$ separa-se de $R_{4}+R_{5}$ exatamente abaixo do término da Sc e termina na margem costal pouco antes do ápice. $R_{4}$ e $R_{5}$ separam-se abaixo do término de $R_{1}$ e terminam pouco antes do ápice na margem costal, depois do ápice na margem externa, respectivamente. $\mathrm{R}_{4}$ paralela a margem costal. Veias $M_{1}, M_{2}$ e $M_{3}$ partem do ápice da célula discal ligeiramente divergentes, $M_{2}$ muito próxima de $M_{1}$ e, $M_{3}$ afastada de $M_{2}$. Veias dcs e $\mathrm{dcm}$ pequenas, aproximadamente 10 vezes menor que dci. A m-cu maior que dci. $\mathrm{CuA}_{1}$ e $\mathrm{CuA}_{2}$ partem da célula discal separadas por uma distância maior que m-cu; $\mathrm{CuA}_{2}$ dista de $\mathrm{CuA}_{1}$ na base por uma distância aproximadamente igual a m-cu. Na base de $\mathrm{CuA}_{1}$ vestígio de pós-cúbito. Veia $2 \mathrm{~A}$ ligeiramente sinuosa entre a base e o ângulo anal.
Asa posterior, delimitada como a anterior, com margem costal pouco convexa a exceção da base. Margem externa côncava entre $\mathrm{Sc}+\mathrm{R}_{1}$ e $\mathrm{R}_{\mathrm{s}^{\prime}}$ passa à convexa até $\mathrm{CuA}_{2}$, voltando ao aspecto inicial para terminar numa pequena projeção caudal. $\mathrm{Sc}+\mathrm{R}_{1}$ termina logo abaixo do ápice fortemente curvada na base, onde encontra a veia umeral $(\mathrm{u})$ voltada para a margem externa. $R_{1}$ separada da $S c$ na porção basal para formar a célula basal. $\mathrm{R}_{\mathrm{s}}$ segue como veia única até a margem externa da asa. A dcs maior que a dcm e menor que dci. CuA bifurca-se em dois ramos, $\mathrm{CuA}_{1}$ e $\mathrm{CuA}_{2} ; \mathrm{m}$-cu praticamente ausente. Intervalo entre as base das veias $\mathrm{CuA}_{1}$ e $\mathrm{CuA}_{2}$ maior que dcs. Duas anais presentes $2 \mathrm{~A}$ termina no ápice do prolongamento caudal e $3 \mathrm{~A}$ na margem interna. Sem escamas odoríferas.

A articulação das asas com o tórax, envolve escleritos de formatos irregulares, os escleritos axilares. Situados entre a base das asas e os processos laterais do tórax. Na asa anterior, o primeiro axilar ( $\left.1^{\circ} \mathrm{ax}\right)$, oblongo, de porção posterior afilada, articulada com o adnotal e anteriormente com a placa suralar II; a porção anterior expandida articula ântero-lateralmente com o 


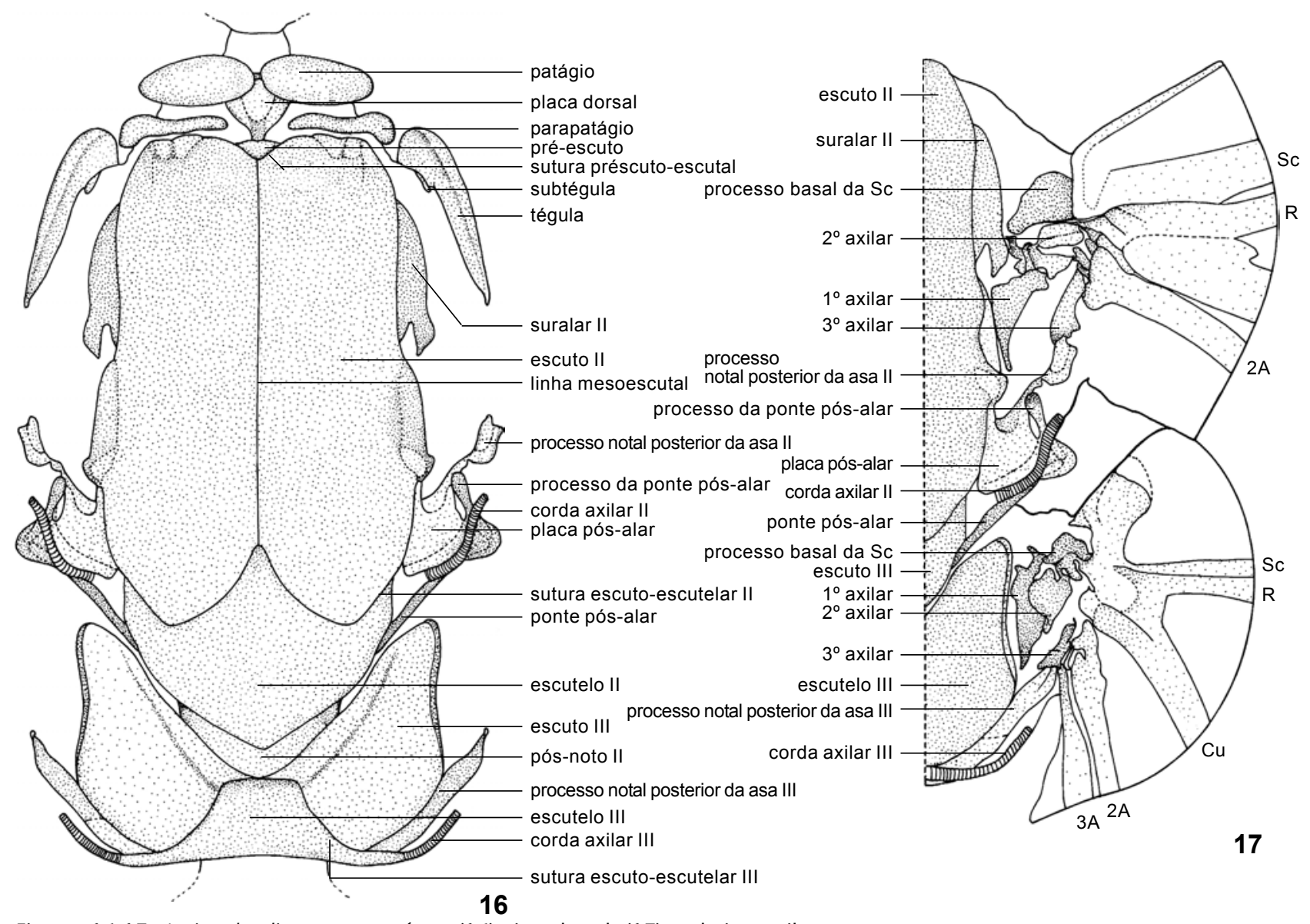

Figuras 16-17. Agrias claudina annetta, tórax: (16) vista dorsal; (17) escleritos axilares.

processo basal da Sc e lateralmente com o segundo axilar. O processo basal da Sc, triangular e globoso, situa-se anteriormente aos primeiro e segundo axilares. Segundo esclerito axilar $\left(2^{\circ}\right.$ ax $)$, bilobado, articula com o primeiro axilar; o lobo anterior está ligado lateralmente ao esclerito radial. Entre o segundo e terceiro axilares um esclerito projetado ventralmente e ladeado por membrana, o terceiro axilar $\left(3^{\circ} \mathrm{ax}\right)$ articula anteriormente com a base das Anais e posteriormente com o prolongamento do processo notal posterior da asa II, numa invaginação do esclerito na membrana.

No metatórax, o primeiro axilar $\left(1^{\circ}\right.$ ax $)$ oblongo, articula com o segundo axilar $\left(2^{\circ}\right.$ ax) na região mediana. Este, irregular, está fusionado com o processo basal da Sc. O terceiro axilar ( $\left.3^{\circ} \mathrm{ax}\right)$ articula ventralmente com o segundo axilar, assim como com o processo notal posterior da asa III internamente e distalmente, com a base das Anais.

\section{Pernas}

Perna protorácica pendular, ou seja, a coxa I articula livremente com a pleura I. Artículos de tamanho similar, com exceção do trocânter, menor. Tarso I uniarticulado nos machos e penta-articulado nas fêmeas; no macho desprovido de cerdas, exceto por duas pequenas e apicais. Fêmeas apresentam um par de cerdas na tíbia e poucos pares apicalmente nos tarsômeros. Coxas meso e metatorácicas fundidas ao tórax e separadas dos epimeros II e III pelas suturas basicostais II e III, respectivamente. A coxa II está divida longitudinalmente pela sutura coxal II, formando anteriormente a eucoxa II e posteriormente o mero II. Entre estes, dorsalmente, um pequeno esclerito, o basicoxito II. A porção interna da coxa é caracterizada por uma região mediana membranosa, onde o trocânter articula. O mero II e a eucoxa II estão fusionados onde também estão os côndilos de articulação com a coxa II (articulação ventral da coxa). Na coxa III, a membrana encontra-se reduzida. Entre a coxa e o fêmur está o trocânter, pequeno e irregular. Fêmur II sem espinhos. Tíbia II com duas linhas de espinhos e dois esporões apicais. Quatro primeiros artículos tarsais com quatro linhas de espinhos de forma ordenada e o último artículo com duas. Coxa III com a margem dorsal reta. Pernas posteriores semelhantes às medianas. Na fêmea, a tíbia I é maior que a coxa I; o primeiro tarsômero da perna protorácica é maior que a soma do compri- 


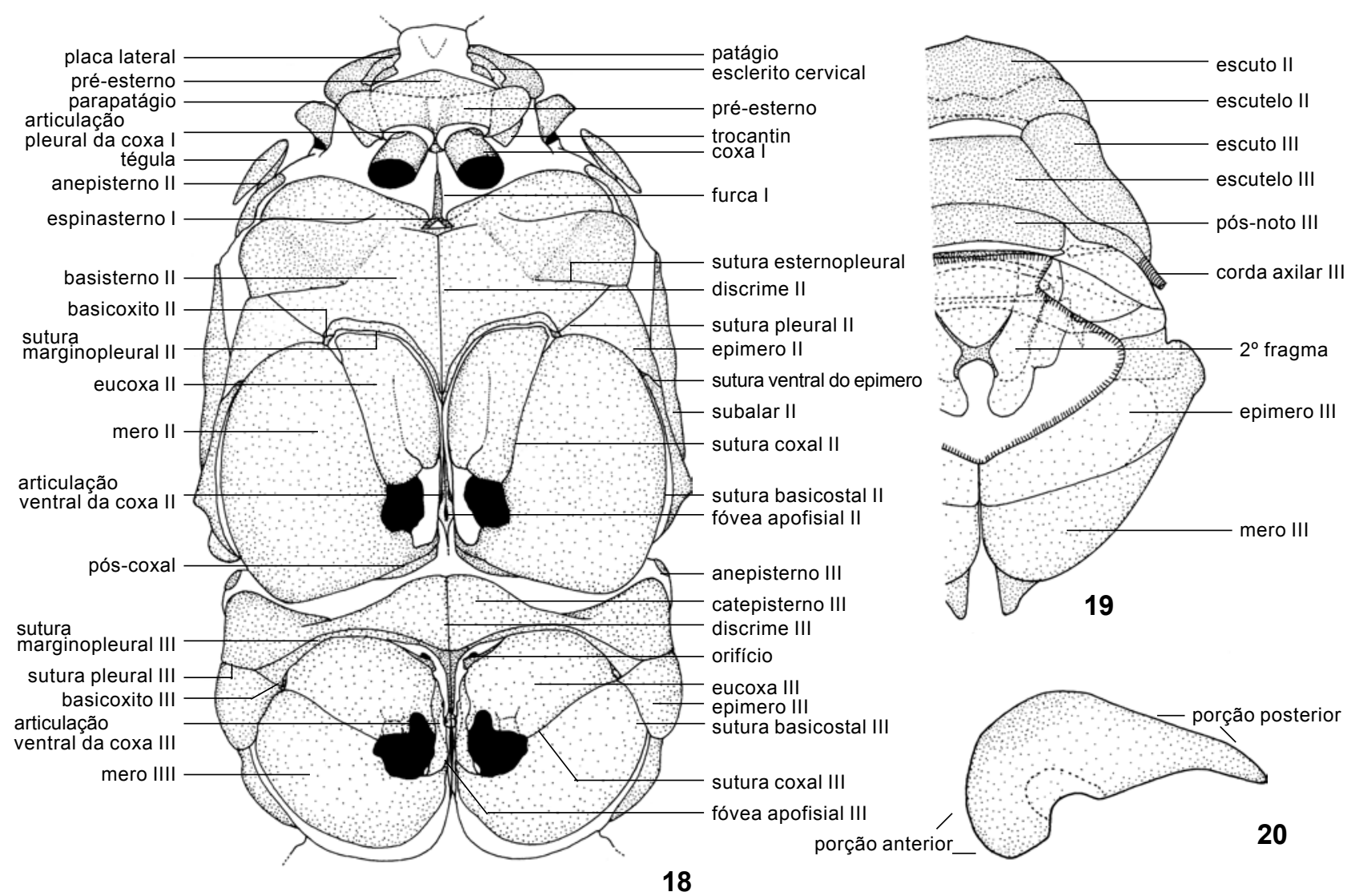

Figuras 18-20. Agrias claudina annetta, tórax: (4) vista ventral; (5) vista posterior do metatórax; (5) vista lateral da tégula.

mento dos demais e nas outras pernas, assim como nos machos, o primeiro artículo possui comprimento semelhante ao dos três seguintes. Distitarso com inúmeras cerdas, na porção póstero-dorsal, algumas longas e pouco projetadas posteriormente. Ventralmente, o distitarso articula com o pré-tarso através da placa ungüitratora pouco diferenciada do pulvilo. Este caracterizado por membrana com quatro projeções laterais alongadas, duas a cada lado. A câmara, placa circular muito esclerotinizada, na porção distal do tarso sustenta uma almofada, o arólio.

\section{Agrias claudina annetta (Gray, 1832)} Figs 15-28

São descritas na seqüência apenas as diferenças observadas com relação à espécie anterior.

\section{Mesotórax}

Noto II, não alargado medianamente. Escutelo II separado parcialmente do escuto II pela sutura escuto-escutelar II. Segundo fragma, bilobado ventralmente com as margens externas em reentrância; caracterizado por partes mais esclerotinizadas, sendo duas bandas nas porções laterais e um X que acom- panha a margem na região mediana, entre os lobos.

Derivando da sutura pleural II, a sutura esternopleural II corre em direção ântero-ventral e termina livre no tegumento. Nota-se apenas uma diferenciação no grau de esclerotinização dos escleritos, não havendo separação total do catepisterno II e basisterno II. O epimero II é dividido longitudinalmente pela sutura ventral do epimero II que corre da porção ântero-ventral até bifurcar-se posteriormente, formando um esclerito triangular, projetado internamente; partindo da região ânterodorsal tem-se a sutura dorsal do epimero II completa.

\section{Metatórax}

Na margem ventral do suralar III encontram-se os processos notais anterior e posterior da asa III, o mediano está ausente. Pós-noto III, póstero-ventralmente ao escutelo III, apresenta-se como uma placa retangular 4,5 vezes mais larga que comprida. Sutura ventral do epimero III surgindo a partir da região médio-ventral do esclerito, dividindo-o.

\section{Asas e escleritos axilares}

Asa anterior possui formato triangular em ambos os sexos; é delimitada pela margem costal convexa em toda a sua

Revista Brasileira de Zoologia 21 (3): 421-433, setembro 2004 


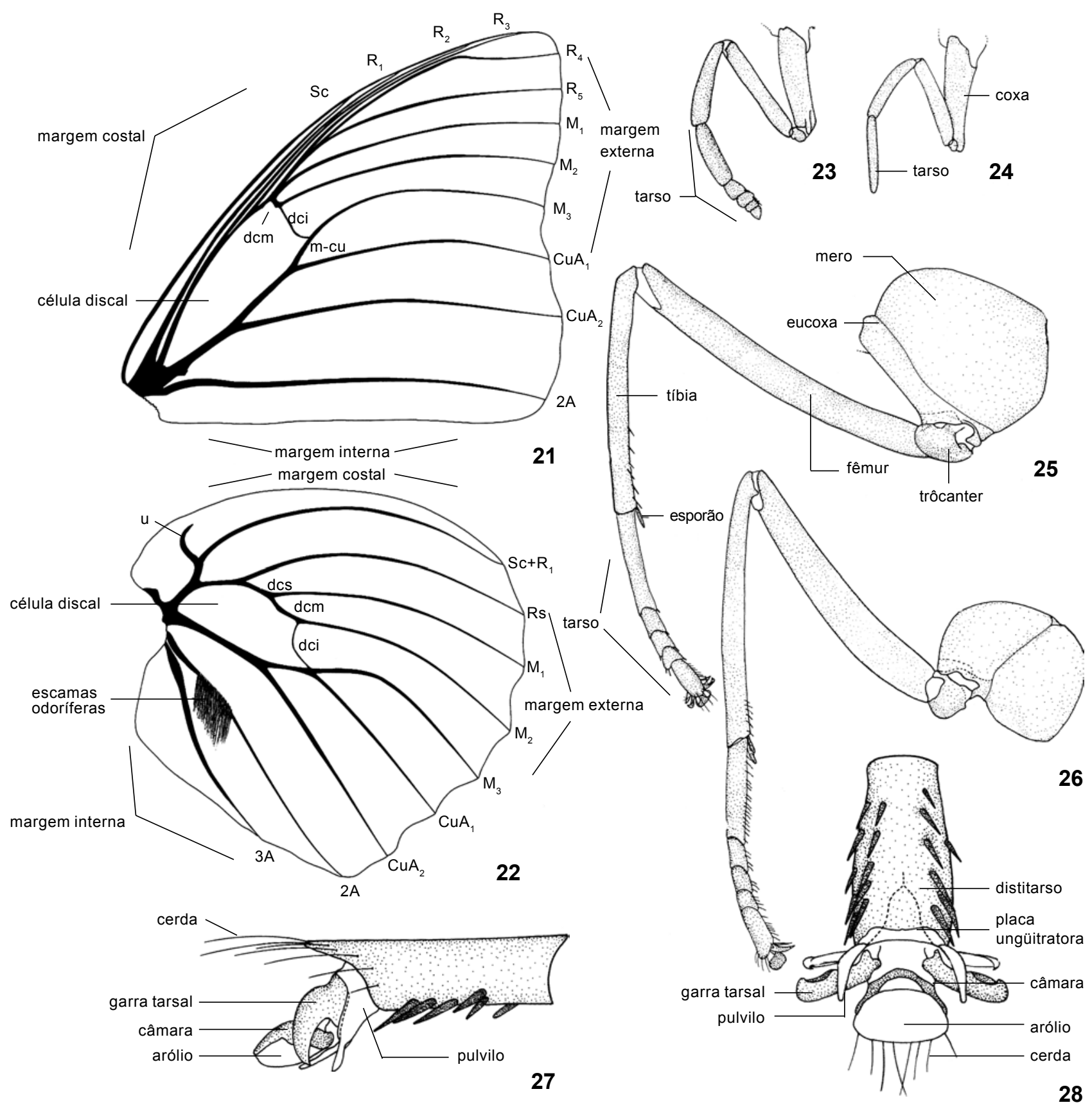

Figuras 21-26. Agrias claudina annetta, (21) asa anterior; (22) asa posterior; (23 - 26) pernas vista lateral: (23) protorácica da fêmea, (24) protorácica do macho, (25) mesotorácica, (26) metatorácica; $(27$ - 28) distitarso (27) vista lateral, (28) vista ventral.

extensão, pela margem externa convexa nos terços superior e inferior e côncava no terço mediano e pela margem interna reta. Radial (R) bifurca-se em $\mathrm{R}_{1}$ e $\mathrm{R}_{\mathrm{s}} ; \mathrm{R}_{1}$ inicia no final do terço mediano da célula discal e termina no início do terço superior da margem costal; $\mathrm{R}_{\mathrm{s}}$ dividida em $\mathrm{R}_{2}, \mathrm{R}_{3}, \mathrm{R}_{4}$ e $\mathrm{R}_{5}$. $\mathrm{R}_{2}$ inicia na célula discal a dois terços de $R_{1}$ e a um terço de $R_{3}+R_{4}+R_{5}$ e termina na margem costal no início do último quarto. $\mathrm{R}_{3}$ separa de $R_{4}+R_{5}$ após a célula discal e termina na margem costal antes do ápice. $\mathrm{R}_{4}$ e $\mathrm{R}_{5}$ separam-se a uma distância equivalente a duas vezes à distância que separa a célula discal da bifurcação

Revista Brasileira de Zoologia 21 (3): 421-433, setembro 2004 
de $\mathrm{R}_{3}$ e $\mathrm{R}_{4}+\mathrm{R}_{5}$ e terminam na margem externa pouco depois do ápice. $\mathrm{R}_{4}$ paralela à margem costal, e abaixo do término de $\mathrm{R}_{2}$, curva para baixo. Veia $\mathrm{dcm}$ pequena, aproximadamente 10 vezes menor que dci. A dcs ausente e a m-cu menor que dci.

Asa posterior, delimitada como a anterior, com as margens costal e externa convexas e sem projeção caudal. $\mathrm{R}_{1}$ fusionada à Sc, sem célula basal. A dcs do mesmo tamanho que dcm e menor que dci. CuA bifurcado em $\mathrm{CuA}_{1}$ e $\mathrm{CuA}_{2}$, veia $\mathrm{m}$-cu vetigial. Duas Anais, $2 \mathrm{~A}$ termina no ângulo anal e $3 \mathrm{~A}$ na margem interna. Escamas odoríferas junto à margem anterior, no terço proximal de $2 \mathrm{~A}$.

Segundo axilar ( $2^{\circ}$ ax) bilobado, cujos lobos articulam com o primeiro axilar; o lobo anterior ligado lateralmente ao esclerito radial.

No metatórax, o primeiro axilar $\left(1^{\circ} \mathrm{ax}\right)$, oblongo, articula com o segundo axilar ( $2^{\circ}$ ax) na região mediana. Este, irregular, fusionado por uma pequena ponte com o processo basal da Sc. Terceiro axilar ( $\left.3^{\circ} \mathrm{ax}\right)$ articula ventralmente com o segundo axilar, assim como com o processo notal posterior da asa III internamente, e distalmente com as veias anais.

\section{Pernas}

Tarso I uniarticulado nos machos ao passo que nas fêmeas penta-articulado; nos machos desprovido de cerdas. Entre a eucoxa II e o mero II, um pequeno esclerito, o basicoxito II. Os quatro primeiros artículos tarsais possuem quatro linhas ordenadas de espinhos, enquanto o último três.

\section{Comparação morfológica}

Na tabela I relaciona-se, resumidamente, as diferenças encontradas entre as espécies em questão.
Comsтock (1961) relata a presença de uma estrutura com formato de veia, que emerge do terceiro axilar posterior, à qual refere-se como veia ambiente. Tal estrutura estaria presente em Zaretis itys itylus e ausente em Agrias claudina annetta. Tal caracter também é considerado por Rydon (1971) em sua chave. Infelizmente, Сомsтоск (1961) não ilustra tal estrutura, descrevendo-a apenas, no entanto, percebe-se uma forte relação da veia com a corda axilar III.

Rydon (1971) propôs a classificação dos Charaxinae por intermédio de chaves que contemplam apenas caracteres dos adultos. Este mesmo autor, embora tenha abordado os imaturos de diversas espécies do grupo, não os utilizou na chave, fato que provavelmente se explica pela inexistência de um número representativo de bionomias de alguns gêneros. Quando da separação de suas duas subfamílias, Zaretidinae (Zaretis Hübner, [1819]) e Preponinae (Agrias Doubleday, 1844), menciona o formato do palpo, o término de $\mathrm{R}_{4}$, formato da asa posterior e escamas odoríferas nas asas como caracteres que as diferenciam.

Além dos caracteres considerados por RYDON (1971) e com base na tabela anterior, outros caracteres foram levantados quanto à distinção de Zaretidina e Anaeina: coloração das antenas, conexão do escuto II e escutelo II, sutura esternopleural, sutura dorsal do epimero II e projeção do primeiro tergo abdominal.

\section{Considerações sobre os Charaxinae}

As apomorfias verificadas nos Charaxinae vêm expressas por EHRLICH (1958b) pela presença de parapatágios esclerotinizados e por RYDon (1971) por apresentarem $\mathrm{R}_{4}$ e $\mathrm{R}_{5}$ muito maiores que o seu ramo comum, com a veia $\mathrm{R}_{4}$ curvada para baixo na proximidade do seu término. Tais afirmações são comprovadas, embora o término de $\mathrm{R}_{4}$ mostre variações nas espécies estudadas.

Tabela I. Comparação resumida das diferenças encontradas entre as espécies analisadas.

\begin{tabular}{lll}
\hline \multicolumn{1}{c}{ Caráter } & \multicolumn{1}{c}{ Zaretis itys itylus } & Agrias claudina annetta \\
\hline Mesotórax dorsalmente & largo medianamente & reto \\
Porção lateral do processo pré-alar & bifurcado & alargado \\
Separação do escuto II e escutelo II & completa & parcial \\
$\begin{array}{l}\text { Razão entre o comprimento e a largura da placa } \\
\text { pós-alar }\end{array}$ & 2 & 1 \\
Margem externa do segundo fragma & Reta & reta com reentrância \\
Formato da porção mais esclerotinizada presente & U invertido & X \\
na margem ventral do segundo fragma & circular & oval \\
Formato do anepisterno II & completa & incompleta \\
Sutura esternopleural & incompleta & completa \\
Sutura dorsal do epimero II & irregular & triangular \\
Formato do basalar II & presente & ausente \\
Processo notal mediano III & 2 & 4,5 \\
Razão entre a largura e altura do pós-noto III & afilada ventralmente e estendida até a & $\begin{array}{l}\text { largura uniforme estendida à mesma } \\
\text { altura da eucoxa III }\end{array}$ \\
Catepisterno + basisterno III & porção mediana da eucoxa III & a
\end{tabular}


Tabela I. Continuação.

\begin{tabular}{|c|c|c|}
\hline Caráter & Zaretis itys itylus & Agrias claudina annetta \\
\hline Região do epimero III onde surge a sutura ventral & ântero-ventral & médio-ventral \\
\hline Ápice da asa anterior & pronunciado & não pronunciado \\
\hline Margem externa (asa anterior) & $\begin{array}{l}\text { côncava nos três quartos superiores e } \\
\text { convexa no quarto inferior }\end{array}$ & $\begin{array}{l}\text { convexa nos terços superior e inferior e } \\
\text { côncava no terço mediano }\end{array}$ \\
\hline Margem interna (asa anterior) & terço distal com reentrância & Reta \\
\hline Início de R1 & fim do terceiro quarto da célula discoidal & fim do terço mediano da célula discal \\
\hline Término de R1 & fim do segundo terço da margem costal & $\begin{array}{l}\text { início do terço superior da margem } \\
\text { costal }\end{array}$ \\
\hline Início de R2 & exatamente entre R1 e R3+R4+R5 & $\begin{array}{l}\text { a dois terços de R1 e um terço de } \\
\text { R3+R4+R5 }\end{array}$ \\
\hline Término de R2 na margem costal & fim do terceiro quarto & início do último quarto \\
\hline Início de R4 e R5 & $\begin{array}{l}\text { metade da distância que separa a célula } \\
\text { discal e início de R3 }\end{array}$ & $\begin{array}{l}\text { dobro da distância que separa a célula } \\
\text { discal e início de R3 }\end{array}$ \\
\hline Término de R4 & na margem costal, não curvando-se & $\begin{array}{l}\text { na margem externa, curvando-se para } \\
\text { baixo }\end{array}$ \\
\hline Veia dcs (asa anterior) & presente & ausente \\
\hline Veia m-cu (asa anterior) & maior que dci & menor que dci \\
\hline Margem costal (asa posterior) & pouco convexa & convexa \\
\hline Margem externa (asa posterior) & $\begin{array}{l}\text { inicialmente côncava entre Sc+R1 e Rs, } \\
\text { passa à convexa até CuA2 e novamente à } \\
\text { côncava para terminar numa projeção } \\
\text { caudal }\end{array}$ & convexa \\
\hline Projeção caudal & presente & ausente \\
\hline Célula basal & presente & ausente \\
\hline Veia m-cu (asa posterior) & praticamente ausente & ausente \\
\hline Escamas odoríferas & ausentes & presentes \\
\hline $\begin{array}{l}\text { Tamanho dos artículos da perna protorácica do } \\
\text { macho }\end{array}$ & similares & diferentes \\
\hline Presença de espinho no protarso do macho & presente (dois) & ausente \\
\hline Fileiras de espinhos no distitarso & duas & três \\
\hline Margem dorsal da coxa III & reta & arredondada \\
\hline $\begin{array}{l}\text { Razão entre os comprimentos do primeiro artículo } \\
\text { tarsal e dos três seguintes }\end{array}$ & 1 & 1,3 \\
\hline Porção póstero-dorsal do distitarso & pouco projetada & bem projetada \\
\hline
\end{tabular}

\section{REFERÊNCIAS BIBLIOGRÁFICAS}

BilotTa, I.G. 1995. Morfologia comparada do tórax das espécies sulbrasileiras de Morphinae (Lepidoptera, Nymphalidae). Revista Brasileira de Zoologia, Curitiba, 11 (4): 691-713.

Bizarro, J.M.; M.M. Casagrande \& O.H.H. Mielke. 2003. Morfologia externa de Thyridia psidii cetoides (Rosemberg \& Talbot). II. Tórax e apêndices (Lepidoptera, Nymphalidae, Ithomiinae). Revista Brasileira de Zoologia, Curitiba, 20 (3): 419-425.

Revista Brasileira de Zoologia 21 (3): 421-433, setembro 2004
BROCK, J.P. 1971. A contribution towards an understanding of the morphology and phylogeny of the Ditrysian Lepidoptera. Journal of Natural History 5: 29-102.

Casagrande, M.M. 1979. Sobre Caligo beltrao (Illiger). III: Morfologia externa do adulto - Tórax (Lepidoptera, Satyridae, Brassolinae). Revista Brasileira de Biologia, Curitiba, 39 (2): 347-355.

Cомsтоск, W.P. 1961. Butterflies of the American Tropics. The genus Anaea Lepidoptera Nymphalidae. A study of the species heretofore included in the genera Anaea, Coeno- 
phlebia, Hypna, Polygrapha, Protogonius, Siderone and Zaretis. New York, American Museum of Natural History, $\mathrm{XIII}+214 \mathrm{p}$.

EHrLich, P.R. 1958a. The integumental anatomy of the monarch butterfly Danaus plexippus L. (Lepidoptera: Danaidae). University of Kansas Science Bulletin, Lawrence, 38 (18): 1315-1349. . 1958b. The comparative morphology, phylogeny and classification of the butterflies (Lepidoptera: Papilionoidea). University of Kansas Science Bulletin, Lawrence, 39 (8): 305-370.

Goel, S.C. \& C.W. Schaefer. 1970. The structure of the pulvillus and its taxonomic value in the land Heteroptera (Hemiptera). Annals of the Entomological Society of America, New York, 63: 307-313.

Hinton, H.E. 1946. On the homology and nomenclature of the setae of lepidopterous larvae, with some notes on the phylogeny of the Lepidoptera. Transactions of the Royal Entomological Society of London 97: 1-35.

Madden, A.H. 1944. The external morphology of the adult tobacco hornworm (Lepidoptera, Sphingidae. Annals of the Entomological Society of America, New York, 27 (2): 145160.

MatsudA, R. 1970. Morphology and evolution of the insect thorax. Memoirs of the American Entomological Institute, Ann Arbor, 4: 431.

Michener, C.D. 1952. The Saturniidae (Lepidoptera) of the western hemisphere. Bulletin of the American Museum of Natural History, New York, 98 (5): 337-501.

Mielke, C.G.C.; O.H.H. Mielke \& M.M. Casagrande. 2004. Estu- do comparado da morfologia externa de Zaretis itys itylus (Westwood) e Agrias claudina annetta (Gray) (Lepidoptera, Nymphalidae, Charaxinae). I Cabeça, apêndices e região cervical. Revista Brasileira de Zoologia, Curitiba, 21 (2): 357-369.

Rydon, A.H.B. 1971. The systematics of the Charaxidae (Lepidoptera: Nymphaloidea). Entomologist's Record and Journal of Variation, London, 83 (8): 219-233, (9): 283287, (10): 310-316, (11): 336-341, (12): 384-388.

Scoble, M. 1992. The Lepidoptera form, function and diversity. Oxford, Natural History Museum Publications, Oxford University Press, 404p.

Sharplin, J. 1963a. Wing base Structure in Lepidoptera I: fore wing base. The Canadian Entomologist, Edmonton, 95: 1024-1050.

. 1963b. Wing base Structure in Lepidoptera II: hind wing base. The Canadian Entomologist, Edmonton, 95: 1121-1145.

SHEPARD, H.H. 1930. The pleural and sternal sclerites of the lepidopterous thorax. Annals of the Entomological Society of America, New York, 23: 237-260.

SNODgrass, R.E. 1935. Principles of insect morphology. New York, Mcgrow-Hill Book Company, 667p.

SORENSEN, J.T. 1980. An integumental anatomy for the butterfly Glaucopsyche lygdamus (Lepidoptera: Lycaenidae): a morphological terminology and homology. Zoological Journal of the Linnean Society, London, 70: 55-101.

STEHR, F.W. 1987. Immature Insects. Dubuque, Publishing Hunt Publishing Company, XIV+754p.

Recebido em 06.VI.2003; aceito em 01.VI.2004. 